\author{
Cadernos de \\ ESTUDOS LINGUÍSTIICOS - (58.1), Campinas, pp. 167-178 - jan./abr. 2016
}

\title{
A VOZ HUMANA NA ERA DAS REDES SOCIAIS ${ }^{1}$
}

\author{
CARLOS PIOVEZANI ${ }^{2}$ \\ PHILIPPE-JOSEPH SALAZAR ${ }^{3}$
}

\begin{abstract}
RESUMO: Encontram-se aqui, inicialmente, uma breve apresentação das razões que conduziram um conjunto de estudos consagrados à análise dos usos e efeitos da voz no discurso político eleitoral brasileiro à proposta de uma pesquisa situada na confluência entre a Análise do discurso e a História das ideias linguísticas sobre os discursos que tratam da voz humana; e, em seguida, uma entrevista sobre a voz, sobre sua importância e seus empregos no contexto da atual onipresença das redes sociais, sobre as obras fundamentais que já refletiram acerca da voz e sobre os riscos de sua perda para a espécie humana com o Prof. Philippe-Joseph Salazar, Distinguished Professor of Rhetoric da Universidade do Cabo, na África do Sul, que é um reconhecido especialista em ópera, voz humana, antropologia social e cultural e interfaces entre retórica e filosofia e cuja formação contou com grandes mestres do pensamento francês dos anos de 1960 e 1970, tais como Louis Althusser, Georges Dumézil, Roland Barthes, Michel Maffesoli e Emmanuel Levinas.
\end{abstract}

Palavras-chave: voz humana; paradigmas grego e latino; redes sociais.

RÉSUMÉ: Tout d'abord, nous expliquerons succinctement comment une somme d'études consacrées à l'analyse des usages et des effets de la voix dans le discours politique électoral brésilien a abouti à la proposition d'une recherche, qui se situe à la confluence entre l'analyse du discours et l'histoire des idées linguistiques sur les discours traitant de la voix humaine; puis, nous présenterons un entretien avec le professeur Philippe-Joseph Salazar, où il sera question de la voix, de son importance et de ses usages, dans un contexte où les réseaux sociaux se font omniprésents, mais aussi des ouvrages fondamentaux qui ont discouru sur la voix et sur les risques que sa perte occasionnerait pour l'espèce humaine. Philippe-Joseph Salazar est Distinguished Professor of Rhetoric de l'Université du Cap, en Afrique du Sud. Il est un spécialiste reconnu de l'opéra, de la voix humaine, de l'anthropologie sociale et culturelle, et des interfaces entre la rhétorique et la philosophie. Sa formation s'appuie sur les grands maitres de la pensée française des années 1960 et 1970, tels que Louis Althusser, Georges Dumézil, Roland Barthes, Michel Maffesoli et Emmanuel Levinas.

Mots-clés: voix humaine; paradigmes grecs et latins; réseaux sociaux.

${ }^{1}$ Este diálogo sobre a voz com o Professor Philippe-Joseph Salazar inscreve-se nas atividades desenvolvidas pelo projeto de pesquisa "Discursos sobre a voz na mídia brasileira contemporânea.", que conta com o financiamento da FAPESP (Processo 2014/09947-3).

${ }^{2}$ Professor da UFSCar e coordenador do Laboratório dos Estudos do Discurso (LABOR/UFSCar) e do Grupo de Estudos da Voz no Discurso (VOX/UFSCar). e-mail: cpiovezani@uol.com.br

${ }^{3}$ Philippe-Joseph Salazar é professor (Distinguished Professor of Rhetoric) da University of Cape Town. e-mail: philippe.salazar@uct.ace.za 
Entre outubro de 2011, o diagnóstico de um câncer de laringe em Luiz Inácio Lula da Silva suscitou uma grande repercussão e uma considerável e heterogênea série de textos sobre os riscos que a doença poderia acarretar para sua voz e, por extensão, para sua atuação na vida pública brasileira. Em vários domínios sociais, emergiram enunciados sobre as possíveis sequelas, de modo que os perigos que ela representava para sua voz tornaram-se tema de conversas cotidianas, de mensagens em redes sociais, de debates entre profissionais da saúde, de comentários da classe política, de notícias e artigos da mídia. Se diante da enfermidade de Lula as sensibilidades políticas e humanitárias afloraram, um interesse científico mais ou menos particular também podia então surgir nos estudos da linguagem: sempre falamos de nossa própria ou da voz de outrem ou o fazemos apenas em certos contextos, movidos por determinados fatores e razões? Especificamente quanto a Lula, o que se diz sobre o papel que sua voz cumpriu no desempenho de sua oratória popular, na composição de seu carisma e em seu sucesso político? Como as distintas posições ideológicas dos enunciadores materializaram-se nesses textos que discorreram sobre a voz de Lula? Por que nas redes sociais as manifestações sobre a voz do ex-presidente eram tão mais agressivas que alhures e quais seriam o estatuto das interações e os modos de presença da voz nesse universo virtual? Com mais forte razão, essas questões tenderiam a ocorrer aos que já estivessem interessados nas relações entre os usos e os efeitos da voz no discurso político.

Desde 2006, por ocasião de nossa pesquisa de doutorado em Linguística e Língua Portuguesa, já havíamos realizado alguns trabalhos que se propuseram a examinar as funções e sentidos das propriedades e inflexões vocais em pronunciamentos políticos brasileiros contemporâneos ${ }^{4}$. Esses trabalhos ocasionaram, em seguida, a proposta e o desenvolvimento do projeto "Discurso sobre a voz na mídia brasileira contemporânea", entre os anos de 2009 e 2013, no Departamento de Letras e no Programa de Pós-Graduação em Linguística da UFSCar ${ }^{5}$. Por seu turno, a execução dessa pesquisa nos impôs a leitura de uma série de obras sobre a voz humana oriundas de diversos campos de conhecimento. Naquele momento, processou-se então uma conjunção entre as análises da voz no discurso político, a leitura de textos que tratavam da voz e a grande repercussão do câncer de laringe de Lula, que nos conduziu à abertura de uma nova frente e à identificação de um novo objeto em nossos estudos: os discursos sobre a voz humana. Noutros termos, o exame dos usos e efeitos da voz no discurso político brasileiro de nossos dias e suas adjacências impeliramnos às interpretações dos dizeres que falam da voz. Em alguma medida, é como se a análise de empregos da voz nos tivesse orientando para uma necessária consideração dos discursos a seu respeito, que, em última instância, são constitutivos das características e das modificações em tais empregos.

\footnotetext{
${ }^{4}$ Ver, por exemplo, Piovezani (2009).

${ }^{5}$ Os resultados dessa pesquisa foram publicados em Piovezani (2010, 2011 e 2013)
} 
Cadernos de ESTUDOS LINGUISTIICOS (58.1) - jan./abr. 2016

Já nos primeiros encaminhamentos desse novo horizonte de pesquisa, deuse uma nossa primeira reflexão sobre o que se diz a propósito da voz: embora a atividade epilinguística seja universal no exercício da fala humana, isto é, em que pese a constância dessa competência que faz com que reitera e ordinariamente falemos de nossa fala, a voz nem sempre se torna objeto dessa nossa fala sobre nossa própria fala. Ao constatarmos esse fenômeno, aventamos a hipótese de que não falamos da voz com as mesmas frequência e intensidade com que falamos em diversos contextos de outros componentes de nossa fala; antes parece haver aí bastante discrição e mesmo ausências a seu respeito. Além disso, o fazemos em circunstâncias nas quais sentimos ou imaginamos existir um problema nos usos da voz, nas quais sentimos ou imaginamos que ela se encontra de alguma maneira em perigo e/ou concentra em si certo poder.

Nossas constatação e nossa suposição não implicam a ideia de que absolutamente pouco se fala da voz. Antes, ela está há muito na boca e na pena dos homens: fala-se dela nas epopeias homéricas, nos diálogos de Platão e na obra de Aristóteles, mas também em livros da Bíblia; falam dela Santo Agostinho, Dante Alighieri e Antônio Vieira, mas também os anatomistas do século XVII (cf. Salazar, 1995, 1999, 2008); fala-se dela nas retóricas, nas medicinas e nas filosofias de outrora e de nossos tempos (Lachenaud, 2013), mas também e não raras vezes na biologia evolutiva e na criação tecnológica desde o século XIX até os dias atuais. Tanto a hipótese que mencionamos logo acima quanto a observação de que falamos com maiores ou menos frequências da voz articulam-se com outra de nossas reflexões: parece-nos que, em determinados contextos da cultura ocidental, a cada ocasião em que uma tecnologia de linguagem tende a representar uma ameaça à voz humana, surge entre nós manifestações em defesa da presença vocal, ou seja, projetam-se alegações em prol da voz ao vivo, tal como podemos verificar nos seguintes casos:

a) diante da invenção da escrita, pode ter surgido a seguinte posição platônica em defesa da oralidade:

A escrita apresenta, meu caro Fedro, um grave inconveniente, que observamos também
na pintura. Com efeito, os seres criados por esta última aparentam ter vida, mas, se lhes
lançamos uma questão, eles permanecerão dignamente em silêncio. A mesma coisa ocorre
com os discursos escritos: poderíamos crer que eles falam como seres racionais; mas se os
interrogamos com a intenção de compreender o que eles dizem, eles se limitam a significar
sempre uma única e mesma coisa. Uma vez escrito, cada discurso vai correr para todos os
lados, e será dirigido indiferentemente àqueles que o conhecem e àqueles que não lhe dizem
respeito; ele ignora a quem ele deve ou não se dirigir. Se vozes discordantes se fazem ouvir
a seu respeito, se ele é injustamente injuriado, ele necessita sempre da ajuda de seu pai.
Sozinho, com efeito, ele é incapaz de refutar um ataque e de se defender por si mesmo.
(PLATÃO, 2002, p.275)

b) a invenção da prensa e dos tipos móveis pode ter contribuído para o advento do culte de la voix à l'âge de l'imprimé, no século XVII (SALAZAR, 1995), que se estendeu no século seguinte na postura de Rousseau (2008, p.116) em prol da fala contra a escrita: 
Ao escrever, somos obrigados a tomar todas as palavras na acepção comum, porém aquele que fala varia as acepções através dos tons, determina-os como deseja; menos obrigado a ser claro, confere maior importância à força e não é possível que uma língua que se escreve conserve por muito tempo a vivacidade daquela que é somente falada.

c) a invenção das várias tecnologias de linguagem, a partir do último quarto do século XIX (telégrafo, microfone, telefone, rádio e cinema mudo), teria concorrido para que Jean Cocteau adotasse esta posição (2002, p. 54:

Antes, a gente se via. A gente podia perder a cabeça, esquecer as promessas, arriscar o impossível, convencer quem a gente ama, se abraçando, se agarrando. Um olhar podia mudar tudo. Mas, com este aparelho, o que acabou, acabou...

d) finalmente, da consolidação dessas tecnologias dos séculos XIX e XX e do advento da internet, poderia ter surgido a atitude de Manoel de Barros (1996, p. 57 e 67$)$ :

Prefiro as máquinas que servem para não funcionar. (...) Não pode haver ausência de boca nas palavras: nenhuma fique desamparada do ser que a revelou.

O mesmo ou ao menos algo análogo ocorre, quando o mundo virtual se estabiliza como espaço incontornável de boa parte de nossas atuais interlocuções e relações sociais? Com os smartphones e as redes sociais, há maiores riscos ou potencialidades para os usos públicos da razão, da fala e da voz humanas? Por que em meio àquelas que seriam as facilidades de interação proporcionadas por essas tantas tecnologias somos ainda instados a falar em público, ao vivo e de viva voz? Sem a pretensão de responder de modo definitivo a essas questões, o diálogo a seguir as formula e as replica, considerando as relações que a fala e voz humana estabelecem com a sociedade e a política, num contexto em que há uma onipresença das tecnologias de linguagem, em particular da internet e das redes sociais.

$* * * *$

Desde o momento em que começamos a realizar as leituras fundamentais a que nos conduziram os estudos que consagramos às funções e sentidos da voz no discurso político e, principalmente, aos discursos sobre a voz em diversas condições de produção, nos deparamos com os textos e obras do Professor PhilippeJoseph Salazar, pesquisador que fora eleito em 1998 diretor do Programa Retórica e democracia, do Collège International de Philosophie de Paris e que a partir de 2004 tornou-se Distinguished Professor of Rhetoric da Universidade do Cabo, na África do Sul. Isso porque o Professor Salazar possui uma sólida formação proporcionada por sua intensa e constante interlocução com grandes mestres do pensamento francês dos anos de 1960 e 1970, tais como Louis Althusser, Georges Dumézil, Roland Barthes, Michel Maffesoli e Emmanuel Levinas, durante e após a qual se tornou um reconhecido especialista em ópera, voz humana, antropologia social e cultural e interfaces entre retórica, política e filosofia. Foi 170 
Cadernos de ESTUDOS LINGUÍSTICOS (58.1) - jan./abr. 2016

com essa condição de especialista nesses objetos e campos do conhecimento que o Professor Salazar publicou, entre outros, os seguintes livros: Idéologies de l'opéra (PUF, 1980); L'intrigue raciale. Essai de critique anthropologique (Klincksieck, 1989); Le Culte de la voix au XVIIème siècle. Formes esthétiques de la parole à l'âge de l'imprimé (Honoré Champion, 1995); L'Art de parler. Anthologie de manuels d'éloquence (Klincksieck, 2003); L'hyperpolitique. Une passion française (Klincksieck, 2009); Paroles de Leaders. Décrypter le discours des puissants (Bourin Éditeur, 2011) e Paroles Armées. Comprendre et combattre la propagande terroriste (Lemieux Éditeur, 2015).

Tal como tende mais frequentemente a ocorrer, deparamo-nos com os escritos antes de nos encontrarmos em pessoa com seu autor. Já conhecíamos algumas dessas obras e havíamos lido alguns desses e de outros textos do Professor Salazar, quando tivemos em março de 2013, por ocasião do Congreso Internacional de Retórica y Interdisciplina, que aconteceu na Universidad de Cuyo, em Mendoza, na Argentina, a oportunidade de encontrá-lo e conhecê-lo pessoalmente. A partir de então teve início um produtivo diálogo, do qual a seguinte entrevista é uma de suas consequências. Conforme o leitor poderá observar, a crítica do Professor Salazar aos comportamentos nas redes sociais, ante as inegáveis perdas que elas produzem e as eventuais potencialidades que talvez possam oferecer, parece ecoar as defesas que Platão, Rousseau, Cocteau e Manoel de Barros, entre outros, fizeram da fala e da voz humana, a cada vez que as técnicas representaram um risco para a construção política dos laços entre os sujeitos de uma sociedade. Cremos que suas palavras possam nos trazer algumas luzes e ideias para que possamos mais bem compreender os fatores e razões que estão fazendo com que este nosso mundo contemporâneo, ao qual não faltam meios materiais de interação e de uso público da razão, se nos apresenta cada vez mais obscuro e virulento.

Carlos Piovezani: Com base em sua condição de filósofo, especialista em Retórica e eminente conhecedor da voz humana e de autor, entre tantas outras obras, dos livros Ideologias da ópera (PUF, 1980), O culto da voz no século XVII (Honoré Champion, 1995), A arte de falar (Klincksieck, 2003), As palavras dos líderes (Bourin Éditeur, 2011), As falas armadas (Lemieux, 2015), nos quais a voz humana sempre esteve presente como um elemento fundamental, como você definiria esses sons articulados em nosso aparelho fonador? A voz humana continua a desempenhar um papel relevante numa era em que ao menos aparentemente muitas das relações entre os sujeitos de nossas sociedades são estabelecidas pelas redes sociais?

Philippe-Joseph Salazar: “A voz humana"? A própria expressão é mais complexa do que parece sê-lo em sua ilusória ingenuidade, assim como em seu caráter imediato e em sua aparente naturalidade. Por essa razão, ela nos impõe uma primeira interrogação: excetuando-se a espécie humana, os animais possuem uma voz? Sem dúvida, eles produzem sons e ruídos; alguns grunhem, outros rugem. Mas, num sentido mais preciso, eles possuem efetivamente uma voz? 
Os antigos romanos, e provavelmente também os indo-europeus, caso fosse feito um estudo etnolinguístico nesta direção, possuíam dois paradigmas para explicar, no Dasein animal e no humano, a aparição, o Erscheinung da voz e do que propriamente não lhe corresponde. O primeiro deles deriva da palavra rumor; o rumor que denotava os ruídos da natureza, os sons do mundo que estão por aí e que se estendem desde o barulho provocado pelo vento nas árvores até os gritos dos animais. Tratava-se da natureza como um fundo sonoro, do qual emergem os brados animalescos, os ruídos da terra e até mesmo alguns sons produzidos pelos humanos, quando estes últimos se aproximam daqueles primeiros, tal como ocorre com a eructação e o soluço, por exemplo. De algum modo, nosso rumor moderno, seja na política, seja na mídia ou seja ainda na sociedade, em geral, pode ser concebido como uma lembrança da selvageria e da ferocidade, frequentemente irracional e agressiva, que pode não raras vezes haver no fundo sonoro das relações sociais de nossos tempos. Já o segundo paradigma compunhase a partir do termo vox, da voz que é aqui exclusiva e eminentemente humana. Provavelmente, os estoicos foram os primeiros a operar esta distinção ou, antes, a teorizá-la, ao procederem à constituição de sua célebre tríade: inicialmente, a phônê, ou seja, o som produzido pela percussão do ar - que é instintiva, entre os animais, e inteligente, no caso dos humanos; em seguida, a phônê, que pode ser transcrita, gramaticalizada e que, em suma, é a voz humana, porque se trata daquela que é "articulada"; e, finalmente, a phône-logos, que é a fala humana articulada e dotada de sentido.

Creio que o que se perde, contudo, nesse sistema e naquele de Aristóteles, nos quais a phônê humana, limitada a certas trocas simbólicas de sentidos políticos e imediatamente submetidas à análise retórica, é uma dimensão, digamos, não grega. Deixe-me tentar explicá-lo: nós podemos refletir sobre a voz mediante uma filiação ao sistema grego, mas também podemos fazê-lo por meio de uma filiação ao princípio latino, uma vez que são eles nossas duas abordagens fenomenológicas fundamentais. A phônê não é a vox: se é na vocalidade da vox que reside e se estabelece o Dasein político, duvido absolutamente que a phônê possua essa mesma função e esse mesmo alcance. Basta, para tanto, que consideremos a proximidade ôntica entre os termos voz e voto, oriundos do latim, para que nos apercebamos da razão pela qual a voz humana é fundamentalmente diferente daquela que seria apenas a fonia. Na projeção da voz, existe um apelo, uma interpelação, um voto e um desejo de efetuar um gesto de presença. Eu dou e doo a voz; promovo um voto de presença. Eu me apresento. Ora, o voto é um ato de compromisso, um gesto de engajamento. No Rig Veda, o Livro dos hinos indianos, a deusa da voz, $V a c$, é primordial porque o que ela simboliza de modo emblemático é justamente o voto, o engajamento, a promessa ${ }^{6}$. Eu dou e doo a voz; eu me coloco diante do outro; eu pro-meto, me comprometo. Com efeito, uma promessa é uma projeção do ser, é uma pro-voc-ação dirigida a outros no intuito de interpelá-los a também engajarem-se. Ao dar e doar a voz, assumo o compromisso de me votar a algo ou a outrem, de me devotar a isso e/ou a aquilo.

\footnotetext{
${ }^{6}$ Conferir Dumézil (1982).
} 
Cadernos de ESTUDOS LINGUISTIICOS (58.1) - jan./abr. 2016

Eis aí uma das principais razões para que somente possamos dizer "voz humana" ou, ao menos, para que apenas possamos pensar na voz como voz humana. Um animal ou uma árvore que emitem sons no rumor do mundo jamais prometem algo ou se comprometem com algo, tal como podemos fazê-lo com a nossa voz. Árvores e animais podem somente estar no mundo com seus sons e ruídos bestiais. No momento em que a política em sentido amplo desce ao nível da bestialidade, nós recaímos então na natureza, bela, mas terrível e estúpida. Grosso modo, a internet é uma das maneiras privilegiadas dessa bestialidade que foi recentemente forjada e que nos sequestra amiúde a voz - com a qual poderíamos nos comprometer com as causas políticas -, sob o pretexto de nos concedê-la. A internet e as redes, supostamente, sociais, desse meu ponto de vista, são antes gregas que latinas. Permita-me avançar uma explicação rápida para essa minha formulação: no fundo da phônê existe a presença do brilho, daquilo que nos coloca sob a luz dos holofotes e do que pode também iluminar os outros, sob diversos ângulos, mas quase sempre em meio a um rumor cada vez mais animalesco e tecnológico. No étimo de phônê, há o morfema phôs, que significa luz em grego; em suma, em fone há fos, tal como encontramos em português na palavra fósforo. Por sua vez, o que chamamos no interior da filosofia de " $f \boldsymbol{e}$ nômeno" consiste na aparição do ser ou do objeto como uma luz. Com um acento fonético aproximado, um herói, nas epopeias de Homero, é também ele chamado de phôs. Noutros termos, trata-se do homem considerado como uma brilhante aparição de algo que é supra-humano do homem e no homem, o que corresponde a um dos sentidos do ser divino.

Com efeito, essa é uma emergência distante, mas bastante provável, de expressões como "quem não aparece não é lembrado", "para ser, é preciso aparecer", "briller par la parole", "publish or perish". Falar da voz humana, seguindo uma linhagem antropológica grega, implicaria dispensar considerável atenção ao fato de que a fala é heroica, na medida em que é a voz dos seres humanos o que torna possível sua ascensão à condição divina, ou seja, à condição de ser capaz de nomear e fazer existir a natureza, sobrepondo-lhe ao fazê-lo, tal como um deus. Mas pode implicar também um extravagante e ilusório desejo: o de (só e a qualquer custo) aparecer. Percebemos então como a voz humana pode concernir ao mesmo tempo a uma representação da interação pela fala e do compromisso político, que ela enseja em vox/votum, e a uma apresentação narcísica e referencial de um poder superior em phônê/phôs. É sempre necessário, numa investigação retórica, política e filosófica, que estejamos atentos a essa dupla linhagem que funda nossa fenomenologia.

Carlos Piovezani: Conforme o mencionamos na apresentação desta entrevista, em nossas reflexões sobre a voz, observamos que, a despeito da onipresença da atividade epilinguística na fala humana, ou seja, dessa faculdade que faz com que constantemente falemos de nossa fala, a voz nem sempre parece estar presente em nosso dizer sobre o dizer. Ante tal observação, formulamos algumas hipóteses sobre a emergência de discursos sobre a voz, segundo as quais postulamos a existência de certa inclinação mais ou menos frequentemente ao silêncio sobre ela, 
caso real ou imaginariamente a voz não desperte problema em sua utilização, não se encontre de algum modo em perigo, tendo em vista o advento de tecnologias de linguagem que pudessem suprimi-la. Há aí a constatação de que somos impelidos a falar e ainda a falar de elementos de nossa própria fala. Nessa direção, respondame por favor o seguinte: no universo virtual, que já foi concebido como o reino de uma inédita liberdade de expressão, por que razão os personagens da vida pública ainda são instados a falar ao vivo e de viva voz? Noutros termos, as tecnologias de comunicação e as redes sociais contemporâneas implicariam modificações e/ou riscos para o exercício de se falar em público?

Philippe-Joseph Salazar: Existe, de fato, um paradoxo: você me pergunta se e por que em um mundo arquinformatizado e super hi-tech, aos políticos e aos homens públicos, em geral, ainda se impõe a necessidade de falar em público, o que ainda é, em muitos contextos, uma ocasião extremamente arriscada. Todos os meios tecnológicos estão aí à disposição para, numa palavra, poder evitar essa necessidade árdua e perigosa que é a de falar e de entrar em contato com a massa; os monarcas e soberanos de outrora já sonharam com esta situação e com esta precisão: falar o mínimo, somente aquilo que é extremamente necessário e, ao mesmo tempo, o que é expressa a exata justiça. Nesse sentido, poderíamos dizer que jamais houve tanta logocracia quanto em nosso tempo, desde a época em que os políticos possuem à sua disposição todos os meios pelos quais poderiam evitar de abrir a boca. Há aí algo ainda mais grave: as pessoas públicas e comuns utilizam as ditas redes sociais como meios arcaicos e pré-lógicos. Twita-se sem a devida reflexão, como se milhares de anos de educação da e para a fala tivessem sido abolidos diante da ilusória crença na força natural do "eu falo". Essas pessoas querem "brilhar", aparecer, estar no phôs, ou seja, querem estar o tempo todo sob os holofotes. A indigência tirânica do discurso contemporâneo, particularmente do discurso político pós-moderno, deve-se essencialmente à conjunção entre o velho desejo de brilhar pela fala e a onipresença aleatória e reificante dos meios eletrônicos de expressão. Não nos enganemos com as aparências ou com um ou outro oásis no deserto: o facebook e todo o resto dessa parafernália são aparelhos repressivos de expressão.

Carlos Piovezani: Diante desse cenário nada entusiasmante, creio que nossas tarefas consistam na reflexão sobre os usos e efeitos dessas tecnologias e dispositivos de fala pública de nossos tempos e na elaboração de críticas, que ao mesmo tempo indiquem suas raras e eventuais potencialidades e demonstrem seus pesados e constantes agenciamentos subjetivos e seus ardilosos entraves na busca por emancipações. Para fazê-lo, necessitamos, sem dúvida, de um aparato teórico e analítico bastante consistente, que trate tanto das formas simbólicas e políticas em geral quanto da fala e da voz humana, em particular. Em sua opinião, quais seriam os textos e as obras incontornáveis já desenvolvidos nas ciências humanas e nos estudos da linguagem a propósito da fala e da voz, que poderiam nos dar alguma luz (phôs, no bom sentido do termo) para entendermos os esgarçamentos nos laços sociais e para nos auxiliar na criação de novos e consistentes votos e compromissos (vox/votum, também em seus melhores sentidos...)? 
Cadernos de ESTUDOS LINGUISTIICOS (58.1) - jan./abr. 2016

Philippe-Joseph Salazar: Tudo depende, parece-me, da versatilidade linguística e teórica do crítico e pesquisador. A tendência é a de que enquanto os filósofos lerão $A$ voz e o fenômeno, de Jacques Derrida (PUF, 1967), os historiadores, por sua vez, e em particular os das religiões, leiam o Apolo sonoro, de Georges Dumézil (Gallimard, 1982). Os estudiosos da Retórica lerão provavelmente $A$ idade da eloquência, de Marc Fumaroli (Droz, 1980), e talvez também busquem ler meu livro O culto da voz no século XVII (Honoré Champion, 1995), que você já mencionou - aqui, ao fazer esse merchandising, o que faço é algo próprio do phôs, mais ou menos negativo de que falei acima. Por seu turno, os linguistas se interessarão pelas notas que Émile Benveniste consagrou a esse respeito em seu $O$ vocabulário das instituições indo-européias (Minuit, 1969). Eu diria que esse conjunto constitui uma base fundamental; esses livros abrem perspectivas e panoramas e conduzem a bibliotecas inteiras. Além da filosofia, da história e dos estudos da linguagem, há a música. No campo da música, como não ler os grandes manuais de canto do século XIX? Ou, ainda, mais ou menos correlato ao âmbito da retórica, há no universo da arte oratória os grandes manuais de elocução e as numerosas histórias da eloquência também do século XIX, período em que a fala pública estava no cerne da política, tal como aponto em meu pequeno livro $A$ arte de falar (Klincksieck, 2003). Possuo uma biblioteca inteira abarrotada por essas obras, na qual mergulho, tão logo deparo-me com um problema social e político antigo ou contemporâneo em que a fala e a voz estão constitutivamente implicadas. Isso tudo, sem mencionar os estudos em outras línguas: há obras importantes em inglês, em alemão, em italiano, em russo e em árabe. Mas, contento-me por ora em lhe falar do domínio francês e, subjacente a ele, do domínio clássico, ou seja, do grego e do latim. Isto é, por ora, contento-me em lhe indicar o que julgo ser o fundamental.

Carlos Piovezani: Em A aula de música (Hachette, 1987), Pascal Quinard, partindo do pressuposto de que tanto a composição musical quanto a atração que a música exerce sobre seus ouvintes repousam ao menos parcialmente na busca incessante por uma voz perdida na infância, avança a ideia de que "Os homens são seres dotados de voz grave e sombria. São aqueles que erram até a morte em busca de uma pequena e aguda voz infantil que abandou sua garganta. (...) A ocasião em que uma criança perde sua voz apenas pode tratarse de uma cena masculina. (...) Às mulheres, a voz é fiel; já aos homens, infiel. Assujeita-os ao abando, à mudança e à troca." Passando ao largo das complexas e importantíssimas relações entre voz e gênero, o que poderia significar a perda da voz para o ser humano?

Philippe-Joseph Salazar: Não estou completamente seguro para responder a essa questão, talvez porque não tenha compreendido completamente $o$ que você quer dizer com "a perda da voz para o ser humano" ou porque as possibilidades de tratar dos riscos dessa perda sejam diversas e variadas. Mas, em todo caso, vou responder à sua pergunta por meio de uma anedota pessoal. Eu piloto aviões; quando o faço, existe em "RT" (rádio telecomunicação) um 
código bastante preciso de contato com a torre de controle. Isso pode ser, por exemplo, um código de abertura de contato: "São Paulo, aqui Serra Zulu Fox Novembro Novembro, bom dia". A esse contato inicial, a torre responderá algo como: "Fox Novembro Novembro, prossiga". Então o piloto informa de onde vem, onde está, qual é o seu avião, o destino para o qual pretende seguir e solicita a permissão da torre para fazer isto ou aquilo na zona em que se encontra. Eis que aqui ocorre algo de vox ou de phônê que sempre amedronta os iniciantes: a torre de controle atribui um squawk, um código de quatro cifras ao piloto, que o adicionará ao seu transponder. É a transmissão desse código que permitirá à torre de controle identificar em seu radar aquele avião, bem como o fará com todos os demais. Sem esse código, a aeronave permanece no radar como um ponto luminoso, ao qual, porém, é impossível afixar uma identificação, ou seja, torna-se impossível relacionar o chamado do rádio e o ponto fosforescente: ele brilha; trata-se de algo relativo ao phôs, mas ele não fala. Ainda em outros termos, o transponder emite um sinal da phônê em direção à torre, que satura e impede a efetiva interlocução pelo rádio. Trata-se do phôs; antes da phônê do que da vox. Com o código, que é exclusivo, me torno um traço e, no momento em que falo, o controlador pode verificar se digo a verdade ou não. Assim, ele pode me endereçar a palavra e eu posso lhe falar via rádio, mas, além disso e ainda mais importante, é o fato de que essa interlocução tem traços, o fato de que ela deixa marcas. Não posso me desviar nem sequer três graus e lhe dizer que continuo ainda na mesma direção. Pois bem, perder a voz seria tornar-se somente um traço, uma marca luminosa sobre uma tela. Um povo sem voz é apenas uma marca para os grupos militares, estatais e mercantis. Os sujeitos sem voz dessa sociedade tornam-se rastreáveis e identificáveis; eles podem emitir sons (o que corresponde ao que os regimes totalitários chamam de liberdade de expressão), mas não podem efetivamente dizer: "Tchau, Controle; correção; estou mudando de direção." Evidentemente, o que recomendo aos companheiros de nossa época é que jamais percam sua voz; recomendo-lhes, ainda, que apaguem os traços de sua voz nas redes sociais, isto é, que façam o que jamais deve ser feito por um piloto: deem uma falsa identificação, façam-se passar por outros. Dessa forma, eles poderão tomar a fala e até mesmo brilhar por seu intermédio, sem que sejam reduzidos a um traço eletrônico com função consumidora, que é o único e exclusivo objetivo do capitalismo selvagem dos facebooks e de todos os outros demais sistemas repressivos de expressão. Nessa era pós-moderna, constituída por uma selvageria social sem precedentes desde o feudalismo, graças à internet, temos a possibilidade de retornar ao "rumor" primordial, de nos dissimularmos no embrutecimento do mundo. Em resumo, talvez tenhamos a possibilidade de não oferecer uma nossa voz fosforescente e o dever de guardar nossa voz aos votos, promessas e provocações, pagando para tanto o preço do anonimato. 


\section{REFERÊNCIAS BIBLIOGRÁFICAS}

BENVENISTE, E. (1969). Le vocabulaire des institutions indo-européennes. Paris: Minuit. (Edição brasileira: $O$ vocabulário das instituições indo-européias. vol. 1 e 2. Campinas: Editora da Unicamp, 1995).

BARROS, M. (1996). Livro sobre o nada. Rio de Janeiro: Record.

COCTEAU, J. (2002). La voix humaine. Paris: Stock.

DERRIDA, J. (1967). La voix et le phénomène. Paris: PUF. Edição brasileira: A voz e o fenômeno. Rio de Janeiro: Zahar, 1994.

FUMAROLI, M. (1980). L'âge de l'éloquence. Rhétorique et res literária de la Renaissance au seuil de l'époque classique. Genebra: Droz.

DUMÉZIL, G. (1982). Apollon sonore. Paris: Gallimard.

LACHENAUD, G. (2013). Les routes de la voix: l'Antiquité grecque et les mystères de la voix. Paris: Les Belles Lettres.

PIOVEZANI, C. (2009). Verbo, Corpo e Voz: dispositivos de fala pública e produção da verdade no discurso político. São Paulo: Editora UNESP.

PIOVEZANI, C. (2010). Ler o discurso político: sons e imagens na produção da verdade em pronunciamentos eleitorais. Leitura. Teoria \& Prática, v. 28, n. 55. p.12-18.

PIOVEZANI, C. (2011). Usos e sentidos da voz no discurso político eleitoral brasileiro. Revista ALFA. São Paulo: UNESP, vol. 55, n. 1. p.163-176.

PIOVEZANI, C. (2013). A voz no feminino: uma análise discursiva de elementos prosódicos num pronunciamento eleitoral de Dilma Rousseff. Fragmentum. (UFSM) "Modos de subjetivação operados pela voz em discurso", organizada por Pedro de Souza. V. 36. p. 15-23.

PLATÃO. (2002). Phèdre. Paris: Belles Lettres.

QUINARD, P. (1987). La leçon de musique. Paris: Hachette.

ROUSSEAU, J-J. (2008). Ensaio sobre a origem das línguas. Campinas: Editora da Unicamp.

SALAZAR, P-J. (1980). Idéologies de l'opéra, Paris: Presses Universitaires de France, 1980.

SALAZAR, P-J. (1989). L'intrigue raciale. Essai de critique anthropologique, Paris: Klincksieck.

SALAZAR, P-J. (1995). Le culte de la voix au XVIIème siècle: formes esthétiques de la parole à l'âge de l'imprimé. Paris: Honoré Champion.

SALAZAR, P.-J. (1999). La voix au XVIIème siècle. In: FUMAROLI, M. (dir.). Histoire de la rhétorique dans l'Europe moderne (1450-1950). Paris: PUF. p. 787-822.

SALAZAR, P-J. (2008). Darwin à Padoue: l'anthropologie de la voix au XVIIè et au XIXè siècles. In: CASSIN, B.; LEVINAS, D. (org.) Vocabulaires de la voix. Paris: L'Harmattan. p. 39-52.

SALAZAR, P.-J. (2003) L'Art de parler. Anthologie de manuels d'éloquence, Paris: Klincksieck.

SALAZAR, P.-J. (2009). L’hyperpolitique. Une passion française, Paris: Klincksieck. 
PIOVEZANI \& SALAZAR - A voz humana na era das redes sociais ...

SALAZAR, P.-J. (2011). Paroles de Leaders. Décrypter le discours des puissants, Paris: Bourin Éditeur.

SALAZAR, (2015). P.-J. Paroles Armées. Comprendre et combattre la Propagande Terroriste, Paris: Lemieux Éditeur. 